\title{
PENGENDALIAN PARASIT UPAYA UNTUK MENINGKATKAN PRODUKTIVITAS SAPI BALI PADA SAPI KANDANG SIMANTRI DI KECAMATAN MENGWI KABUPATEN BADUNG BALI
}

\author{
I.A.P. Apsari ${ }^{1}$, I.B.N. Swacita ${ }^{2}$, G.A.Y. Kencana ${ }^{3}$, A.A.S. Kendran ${ }^{4}$, I K. Suada ${ }^{5}$
}

\begin{abstract}
ABSTRAK
Tujuan kegiatan pengabdian kepada mayarakat ini adalah untuk dapat meningkatkan produktivitas sapi bali di kecamatan Mengwi Badung, melalui upaya pengendalian penyakit akibat parasit. Sapi yang terus berada di kandang tidak mengurangi kemungkinan terinfeksi oleh parasit. Sistem pertanian terintegrasi (SIMANTRI), cara pemeliharaan sapi dengan terus berada di kandang Simantri. Target khusus yang ingin dicapai adalah mengendalikan penyakit cacingan dan ektoparasit pada sapi kandang Simantri di kecamatan Mengwi Badung. Sasaran kegiatan ini adalah petani ternak Simantri yang memelihara sapinya dengan cara dikandangkan, sesuai kandang Simantri. Metode yang diterapkan untuk tercapainya tujuan kegiatan ini adalah melakukan spraying dan pemberian obat cacing langsung ke peternak Simantri di kecamatan Mengwi Badung untuk pengendalian penyakit parasit. Pengabdian kepada masyarakat di desa Penarungan Mengwi Badung berupa pelayanan kesehatan pada ternak sapi kandang Simantri, telah dilakukan pada tanggal 8 September 2017. Simpulan dari kegiatan pengabdian kepada masyarakat di desa Penarungan Mengwi Badung berupa pelayanan kesehatan telah berhasil dilaksanakan dengan baik. Saran dari evaluasi hasil kegiatan ini, disarankan untuk menyertai pemberian obat anti protozoa disamping obat cacing dan vitamin pada ternak sapi kandang simantri.
\end{abstract}

Kata Kunci : kandang Simantri, produktivitas, spraying, obat cacing, Mengwi

\begin{abstract}
The purpose of community service is to improve the productivity of bali cattle in Mengwi Badung subdistrict, through the effort of parasitic disease control. Cattle that continue to be in the cage do not reduce the possibility of being infected by the parasite. Integrated farming system (SIMANTRI), how to keep the catle by continuing in the cage Simantri. Specific targets to be achieved are controlling worms and ectoparasites in Simantri cattle in Mengwi Badung district. The target of this activity is Simantri livestock farmers who keep their cattle in a way, according to Simantri cage. The method applied for the achievement of the purpose of this activity is to spraying and administering the worm drugs directly to Simantri farmers in Mengwi Badung sub district for parasitic disease control. The community service in village Penarungan Mengwi Badung was that of health services in Simantri cage cattle, was done on September 8th, 2017. Conclusions from community service activities in the village Penarungan Mengwi Badung in the form of health services has been successfully implemented properly. Suggestions of this activity, it is advisable to accompany the provision of anti-protozoan drugs in addition to the worm drugs and vitamins in Simantri cattle.
\end{abstract}

Keywords : Simantri cage, productivity, spraying, worm drugs, Mengwi

\footnotetext{
${ }^{1}$ Lab.parasitologi, Fakultas Kedokteran Hewan Universitas Udayana e-mail :iapapsari@yahoo.co.id

${ }^{2}$ Lab.Kesehatan masyarakat Veteriner; Fakultas Kedokteran Hewan Universitas Udayana

${ }^{3}$ Lab. Virologi, Fakultas Kedokteran Hewan Universitas Udayana

${ }^{4}$ Lab. Patologi Klinik, Fakultas Kedokteran Hewan Universitas Udayana

${ }^{5}$ Lab.Kesehatan masyarakat Veteriner; Fakultas Kedokteran Hewan Universitas Udayana
} 


\section{PENDAHULUAN}

Mengwi adalah sebuah kecamatan di kabupaten Badung Bali yang luasnya $8200 \mathrm{~km}^{2}$ dengan jumlah penduduk \pm 501.126 jiwa (Kecamatan Mengwi, 2014), terdiri atas 18 desa dengan 5 kelurahan. Kecamatan ini juga merupakan ibukota kabupaten. Melihat data populasi ternak sapi yang ada di kabupaten Badung, jumlah sapi yang ada di kecamatan Mengwi (8.102) termasuk sedikit dibanding dengan Abiansemal (13.461) dan Petang (30.390) (Badung Dalam Angka, 2011). Salah satu upaya untuk menjaga dan meningkatkan populasi sapi bali adalah program Simantri terutama di Mengwi. Simantri bertujuan untuk meningkatkan kesejahteraan petani dan juga melestarikan sapi bali sebagai plasma nutfah khas Bali (Pastika, 2011).

Bali mulai tahun 2009 telah memperkenalkan Simantri, yaitu sistem pertanian terintegrasi. Tujuan dikembangkan program Simantri adalah untuk mendukung berkembangnya diversifikasi usaha pertanian secara terpadu dan berwawasan agribisnis. Tambahan sumber pendapat melalui integrasi tanaman dan ternak. Sementara itu, tatalaksana perkandangan sampai saat ini belum sepenuhnya mendapat perhatian yang serius, sehingga faktor produksi tidak dapat maksimal terutama pada peternakan rakyat. Kecamatan Mengwi juga telah banyak yang mengadopsi program Simantri. Data menurut Suluhbali (2016) bahwa dari 479 Simantri di seluruh Bali terdapat 13\% yang mengalami masalah atau istilahnya sakit.

Permasalahan yang ada adalah pada peternak yang melaksanakan program Simantri, tetapi perkandangannya tidak dikelola dengan baik. Sapi pada kandang Simantri dapat terinfeksi oleh Ekto dan Endoparasit apabila keadaan perkandangannya yang kotor, becek, kurang sinar matahari. Kandang dengan sistem drainase yang kurang baik, sehingga kotoran menumpuk akan mengundang lalat. Lalat (Musca larvipara) dapat berperan sebagai penular cacing mata (Thelazia sp) pada sapi (Soulsby, 1982). Penyakit akibat cacing mata dapat menyebabkan ternak sapi terganggu sehingga nafsu makan menjadi menurun, akhirnya kerugian ekonomi karena bobot sapi menurun (Zajac and Conboy, 2007). Kondisi kandang yang mendukung perkembangan parasit berakibat endoparasit berkembang dengan baik, sehingga infeksi berulang dapat terus berlanjut, seperti perkembangan ookista Coccidia. Infeksi koksidiosis pada sapi yang dikandangkan berpeluang tinggi kejadiannya (Levine, 1995).

Peternak yang pemeliharaan sapinya menerapkan sistem Simantri tentunya berharap ternaknya sehat dan produktif sesuai tujuan pemeliharaannya. Peternak yang menjadikan satu-satunya sumber pendapatan dari hasil ternak sapi tersebut, menginginkan hasil ternak dapat meningkatkan pendapatannya. Ternak yang dapat meningkatkan pendapatan karena ternaknya produktif yaitu sehat, reproduksinya lancar (menghasilkan anak atau daging dengan optimal).

Hasil penelitian mahasiswa pada sapi di sekitar sentra pembibitan sapi bali di desa Sobangan diperoleh bahwa infeksi oleh parasit gastrointestinal pada sapi bali cukup tinggi $(21 \%$ cacing nematoda) (Fadli, 2013). Infeksi parasit cacing menyebabkan kerugian ekonomi yang besar terutama pada peternakan rakyat (McManus dan Dalton, 2006). Infeksi cacing ringan dan sedang menimbulkan gejala klinis yang nyata, sedangkan infeksi berat dapat menyebabkan terhambatnya pertumbuhan pada ternak muda (Subekti et al., 2007). Berdasar ketinggian tempat di kecamatan Mengwi adalah yang termasuk wilayah dataran rendah basah, maka kelembaban yang tinggi dan suhu udara memungkinkan sebagai kondisi optimal bagi perkembangan ekto dan endoparasit. Menurut Al-Shaibani et al.(2008) suhu optimal untuk perkembangan stadium telur dan larva infektif dari cacing nematoda adalah $18,3^{\circ} \mathrm{C}-34^{\circ} \mathrm{C}$, demikian pula sesuai bagi perkembangan dari ookista Coccidia (Levine, 1995). 
Berdasar analisis situasi diatas dapat disusun permasalah adalah bagaimana kondisi ternak sapi saat sebelum kegiatan pengabdian dan setelah dilakukan pengabdian.

untuk meningkatkan produktivitas sapi bali melalui pengendalian penyakit akibat parasit pada sapi kandang Simantri di kecamatan Mengwi. Kegiatan ini didahului survey pada ternak sapi pada kandang Simantri di Mengwi, mengenai data infeksi akibat parasit serta yang sakit. Kegiatan pengabdian ini dengan melalui pengendalian penyakit parasit yaitu kegiatan spraying dan memberikan pengobatan berupa obat anti parasit serta pemberian vitamin pada ternak sapi kandang Simantri di kecamatan Mengwi, dengan harapan dapat meningkatkan produktivitas sapi di mengwi.

Peternak dapat pelayanan kesehatan bagi ternaknya sendiri secara cuma-Cuma. .Peternak mendapat pengetahuan mengenai pemeliharaan ternak sapi terutama managemen kesehatan yang terkait dengan kejadian infeksi parasit pada ternak sapi. Peternak menjadi sadar bahwa infeksi parasit secara tidak langsung dapat merugikan bagi ternaknya sendiri akibat pertumbuhannya terganggu

Permasalahan yang ada pada sapi kandang Simantri yaitu dapat terjadi tingginya infeksi parasit (ekto dan endoparasit) pada ternak sapi. Karena di Mengwi telah diterapkan program Simantri, maka kolaborasi antara pertanian dan peternakan harus selaras. Sebagai alternatif pemecahan masalah dalam hal ini gabungan kelompok tani ternak (gapoktan) diberdayakan agar lebih memperhatikan sistem perkandangan sapi Simantri untuk mengurangi kerugian peternak-peternak akibat infeksi parasit. Perhatian dalam bentuk memberi layanan kesehatan dan penyuluhan mengenai manajemen pemeliharaan ternak sapi pada program Simantri bagi peternak di kecamatan Mengwi.

\section{METODE PELAKSANAAN}

Metode yang diterapkan untuk tercapainya tujuan kegiatan ini adalah pengendalian ektoparasit dengan melakukan spraying pada sekitar kandang Simantri dan pemberian obat anti endoparasit secara langsung ke ternak yang ada di kandang Simantri di wilayah desa Penarungan Mengwi Badung. Disamping itu disertai juga dengan penyuluhan secara personal tentang cara pengendalian penyakit parasit melalui memelihara kebersihan kandang dan kebersihan lingkungan yang nantinya sebagai sumber infeksi melalui kandang. Untuk dapat meningkatkan produktivitas maka kondisi sapi harus dimaksimalkan melalui pemberian vitamin yang nantinya berdampak bagi kesehatan sapi untuk menjadi produktif.

\section{HASIL DAN PEMBAHASAN}

Telah dilakukan pengabdian kepada masyarakat di desa Penarungan Mengwi Badung pada hari Jumat tanggal 8 September 2017. Sasaran kegiatan pada saat ini adalah kelompok petani ternak Simantri. Di desa Penarungan terdapat dua kelompok tani ternak yaitu kelompok Kembang Lestari dan Merta Jaya.

Kelompok tani ternak Simantri di desa Penarungan sangat senang menerima kedatangan kami saat kegiatan ini. Mereka sangat antusias mendengarkan saran kami mengenai cara pengendalian penyakit melalui menjaga kebersihan kandang. Mereka sangat senang menerima bantuan obat untuk mengendalikan ektoparasit terutama untuk mengusir lalat. Peternak menyadari bahwa hadirnya lalat di sekitar kandang dapat mengganggu nafsu makan sapi sehingga menurunkan

VOLUME 17 NOMOR 2, APRIL 2018 | 86 
kondisi sapi akhirnya penyakit menjadi mudah menginfeksi sapi. Termasuk dalam hal ini penyakit cacingan. Sapi yang terus berada di kandang seperti sapi kandang Simantri, sangat rentan terinfeksi oeh protozoa coccidia, terutama pedet. Menurut laporan ketua kelompok Simantri sebelumnya ada anak sapi yang mati diduga akibat terinfeksi oleh protozoa pencernaan, karena gejala yang terlihat berupa mencret yang encer dan berdarah.

Evaluasi hasil pengabdian yang telah dilaksanakan perlu dilakukan. Evaluasi berupa pemeriksaan feses saat sebelum pemberian obat cacing dan seminggu berikutnya pengambilan feses dan pemeriksaan hasilnya. Hasil pemeriksaan ini sebagai laporan evaluasi keberhasilan pengabdian yang dilaksanakan berupa pemberian obat cacing dan melakukan penyemprotan anti ektoparasit atau lalat.

Pemeriksaan feses sebelum dilakukan pengobatan telah dilakukan, kemudian dilakukan pemeriksaan feses seminggu setelah pengabdian member hasil yang baik. Terjadi hasil negative terhadap infeksi endoparasit terutama parasit cacing. Hanya saja pemeriksaan tehadap ookista Coccidia masih positif ada pada sapi yang dewasa. Hal ini terjadi karena pemberian obat anti protozoa hanya diberikan pada pedet saja, sementara untuk yang dewasa tidak dilakukan. Dengan kejadian ini perlu diberikan anti protozoa untuk semua sapi di kandang Simantri, karena ookista yang dikeluarkan oleh sapi dewasa ini menjadi sumber penular bagi pedet yang sangat peka terhadap infeksi Coccidia. Pelaksanaan kegiatan pengabdian ini dapat dilihat pada Gambar 1-3.
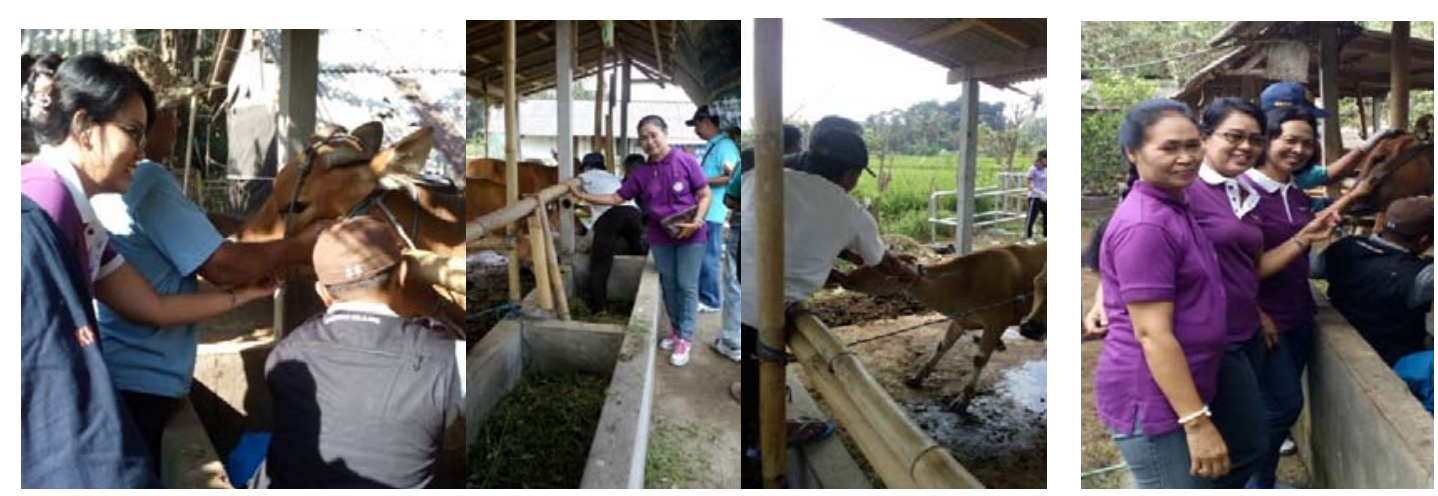

Gambar 1. Kegiatan pengabdian di desa Penarungan pada Kelompok Ternak Simantri Merta Jaya dan Kembang Lestari
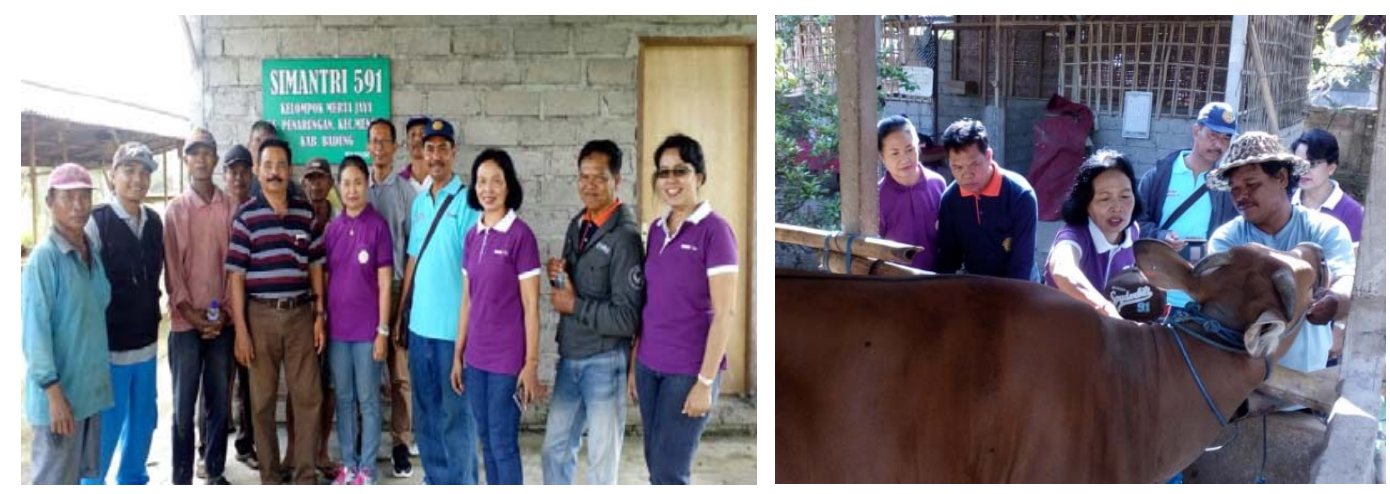

Gambar 2. Pelaksanaan Pengabdian pada kelompok Ternak Simantri, upaya menenangkan sapi untuk pemberian obat cacing 


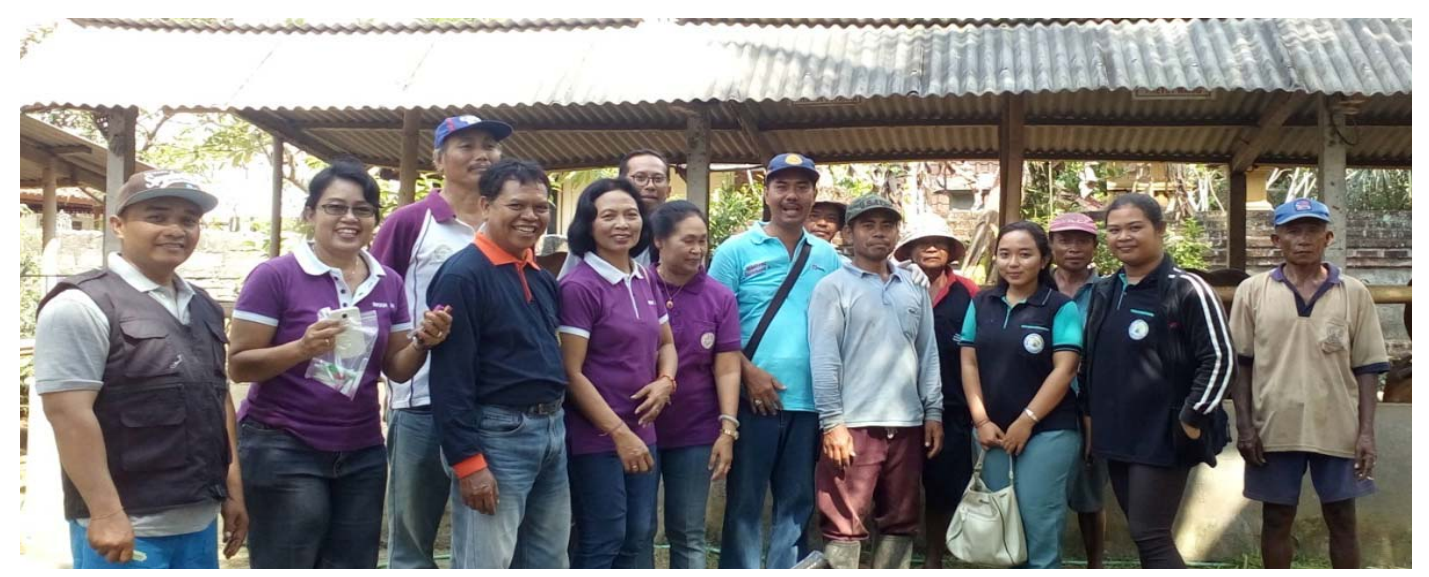

Gambar 3. Personil dalam pelaksanaan pengabdian masyarakat bersama kelompok ternak Simantri Desa Penarungan dan Pendamping Simantri

\section{SIMPULAN DAN SARAN}

Kegiatan pengabdian kepada masyarakat di desa Penarungan kecamatan Mengwi Badung Bali telah berhasil dilaksanakan dengan baik.

Disarankan untuk menyertakan pemberian obat anti koksidia pada sapi kandang Simantri terutama pada pedet dan juga pada sapi dewasa disamping pemberian obat cacing Pengendalian penyakit parasit akan dapat meningkatkan produktivitas sapi.

\section{UCAPAN TERIMAKASIH}

Terimakasih penulis sampai kepada Rektor, Ketua LPPM dan Dekan FKH Unud atas dana dan fasilitas serta dukungan morilnya. Tidak lupa terimakasih penulis sampaikan kepada Dinas Pertanian dan Pangan Kabupaten Badung, Kepala UPT Dinas Pertanian dan Pangan Kecamatan Mengwi Badung, Kelompok Ternak Simantri Merta Jaya dan Kembang lestari Desa Penarungan Kecamatan mengwi Kabupaten Badung atas ijin dan fasilitas untuk melakukan pengabdian masyarakat di desa Penarungan Mengwi badung.

\section{DAFTAR PUSTAKA}

Al-Shaibani, I.R.M.; M.S.Phulan; A.Arijo and T.A.Qureshi. 2008. Contamination of Infective Larvae of Gastrointestinal Nematodas of sheep on Communal Pasture. International Journal of Agriculture and Biology. 10: 653-657.

Badung Dalam Angka (2011). Data ternak Kabupaten Badung. Pemerintah Provinsi Bali.com.

Fadli, M. 2013. Prevalensi Nematoda Gastrointestinal pada Sapi bali yang Dipelihara Peternak di Sekitar Sentra pembibitan sapi Bali Desa Sobangan Kecamatan mengwi kabupaten Badung. Skripsi. Fakultas keokteran Hewan Universitas Udayana.

Kecamatan Mengwi (2014). Mengwi Badung. Wikipedia.com

Levine, N.D (1995). Protozoologi Veteriner. Penerjemah Soeprapto Soekardono. Gadjah Mada University Press

McManus, D.P. dan J.P.Dalton. 2006 Vaccine against the zoonotic trematodes Schistosoma japonicum, Fasciolahepatica and Fasciola gigantic. Parasitol.133(S2): 543-562.

Pastika, M (2011). Selain dorong kesejahteraan, Simantri juga lestarikan sapi Bali. Website Resmi Pemerintah Provinsi Bali. Pemerintah Provinsi Bali.com 
Soulsby, E.J.L1 (1982). Helminth, Arthropods and Protozoa of Domestic Animals. $7^{\text {th }}$ Ed. Bailliere Tyndall. W.B. Saunders. London

Subekti,S.; S.Mumpuni, dan Kusnoto. 2007. Ilmu Penyakit Nematoda Veteriner. Departemen Pendidikan dan Kebudayaan. Fakults Kedokteran Hewan Universitas Airlangga, Surabaya. 